\title{
Review Article \\ The Efficacy of Strontium and Potassium Toothpastes in Treating Dentine Hypersensitivity: A Systematic Review
}

\author{
B. F. A. Karim ${ }^{1}$ and D. G. Gillam ${ }^{2}$ \\ ${ }^{1}$ Dental Institute, Kings College London, Floor 18, Tower Wing, Guys Hospital, London SE1 9RT, UK \\ ${ }^{2}$ Centre for Adult Oral Health, Institute of Dentistry, Barts and the London School of Medicine and Dentistry, Queen Mary University, \\ London E1 2AD, UK
}

Correspondence should be addressed to D. G. Gillam; d.g.gillam@qmul.ac.uk

Received 18 October 2012; Revised 27 January 2013; Accepted 25 February 2013

Academic Editor: Dimitris N. Tatakis

Copyright ( 2013 B. F. A. Karim and D. G. Gillam. This is an open access article distributed under the Creative Commons Attribution License, which permits unrestricted use, distribution, and reproduction in any medium, provided the original work is properly cited.

\begin{abstract}
Objectives. The aim of the present paper was to review the published literature in order to identify all relevant studies for inclusion and to determine whether there was any evidence of the efficacy of strontium and potassium toothpastes in the treatment of dentine hypersensitivity (DH). Methods. Following a review of 94 relevant papers both from searching electronic databases (PUBMED) and hand searching of relevant written journals, 13 studies were identified, and 7 papers ( 1 for strontium-based toothpastes and 6 for potassium-based toothpastes) were finally accepted for inclusion. The main outcome measures were the methodology and assessment used by Investigators in studies designed to evaluate DH. Results. The results of the present paper would indicate that the reported efficacy of both strontium- and potassium-based toothpastes in relieving DH is questionable. Conclusions. The results from the present paper would appear to support the conclusions of previous investigators that there is only minimal evidence for the efficacy of both strontium- and potassium-based toothpastes in relieving symptoms of DH.
\end{abstract}

\section{Introduction}

Dentine hypersensitivity $(\mathrm{DH})$ is a relatively common dental condition which may have a profound effect on the quality of life of those who suffer with the problem. The main presenting symptom is pain generally in response to cold stimuli. It is also evident from the published literature that $\mathrm{DH}$ may be underreported by dental professionals who may have problems in the diagnosis and management of the condition $[1,2]$. There are a number of products that have been formulated for either in-office or over-the-counter (OTC) applications, and the mechanism of action of these products appears to work (as evaluated in laboratory-based studies) either on the basis of their tubular occluding properties, for example, restoratives materials such as resins, varnishes, and toothpastes, or by nerve desensitization, for example, potassium-based (chloride, citrate, and nitrate) products [3]. Generally speaking the application of an in-office product may be limited to patients with severe $\mathrm{DH}$ limited to one or two affected teeth whereas the recommendation of an OTC product such as a toothpaste or mouthwash may be suitable for patients or consumers with generalized mild to moderate $\mathrm{DH}$ [3]. One of the problems when evaluating the efficacy or perceived success of these products is that pain is very subjective and the pain experience may vary from individual to individual [4]. The evaluation of these products is generally conducted by dental professionals in a clinical study that would determine the efficacy or effectiveness of a desensitizing product compared to a placebo, negative, or positive control [5]. The duration of these studies would be determined to some extent as to whether the product was an in-office or OTC product and the clinical claims to be made, for example, instant relief from $\mathrm{DH}$ and/or long-lasting relief $[5,6]$. There are a number of problems associated with these studies, for example, the variation of the methodology employed and whether they are typical of the stimuli or sensation experienced by patients and consumers in day-today experience [4]. A further concern from these studies may be related to whether the study population is truly representative of the individual suffering from $\mathrm{DH}$ in the general 
community. Although there is evidence from the published literature that these products have demonstrated measurable positive improvements in terms of percentage reductions from baseline values, it is difficult to determine the clinical relevance of such reductions in individuals with DH [5, 7-9]. Ideally a true end-point or clinical outcome from these studies would be the complete absence of discomfort following the application of a product in the in-office situation or relief of discomfort over time when using an OTC product that may enable an individual to have an accepted quality of life without the previously perceived discomfort $[4,5]$. Currently no universally accepted OTC product that completely relieves the symptoms of DH appears to be available although there are a number of products that have been formulated for the treatment and management of $\mathrm{DH}$ which have demonstrated varying degrees of effectiveness. For example, products that have been shown to act as tubular occludents, such as strontium-based toothpastes, Pro-Argin-based toothpastes containing arginine and calcium carbonate, hydroxyapatite and NovaMin (calcium sodium phosphosilicate) toothpastes or products that act as a nerve desensitiser (e.g., potassiumbased products) [3,10-12]. The aim of the present paper was therefore to identify all relevant studies from the available published literature in order to determine whether there was any evidence of the efficacy of a tubular occludent (strontium) and a nerve desensitiser (potassium) toothpaste for the treatment of $\mathrm{DH}$. The objective was also to update the results from previous reviews for potassium-based toothpastes [710] and strontium-based toothpastes [11], respectively, in the published literature up to 31st December 2010 using an agreed search protocol based on a modified version of Poulsen et al. [9] and Hsui [13].

\section{Aim and Objectives}

The aim of this paper was to examine the available published literature in order to determine the efficacy of both strontium (Sr) (chloride and acetate) and potassium $\left(\mathrm{K}^{+}\right)$(nitrate, citrate, and chloride) toothpastes in the treatment of $\mathrm{DH}$.

\section{Methodology}

The search methodology used for the present study was based on a modified version of Poulsen et al. [9] and Hsui [13] as indicated later.

\subsection{Selection Criteria}

3.1.1. Types of Study. This review included any type of studies (e.g., randomized controlled clinical trials) in which strontium and/or potassium-containing toothpastes/gels were compared to nonpotassium and/or nonstrontium toothpastes.

3.1.2. Types of Participants. Included criteria for the relevant studies were dentate, healthy human adults (at least 18 years of age) with a known history of $\mathrm{DH}$ from exposed root dentine surfaces.
3.1.3. Types of Interventions. This includes the daily home use of strontium and/or potassium-containing toothpastes/gels compared to control toothpastes/gels. In each study the toothpastes compared will either both contain fluoride or have no fluoride. The control toothpaste was exactly the same as the test toothpaste apart from the addition of either a strontium or potassium salt.

3.1.4. Types of Outcome Measures. This includes changes in (1) pain symptoms in response to the test procedures, including tactile, thermal, and air blast stimuli, or (2) patients' subjective assessment of pain during their daily experience. Only studies that reported data after 6 and 8 weeks were included in the review.

\section{Search Strategy}

The search strategy included using hand searching or electronic databases (e.g., PUBMED) up to 31st December 2010. The hand searching process also included examining relevant published or incomplete journals in English. The searching key words in PUBMED were (cervical OR tooth OR teeth OR dentin* OR dental) AND (sensitiv* OR hypersensitiv* OR pain*) AND (Efficacy ${ }^{*}$ ) AND (random* OR trial OR (randomized controlled trial [pt]) OR (controlled clinical trial [pt]) OR cohort* OR longitudinal* OR "follow up" OR prospective ${ }^{*}$ OR case-control).

\section{Statistical Analysis}

Statistical analysis of data from these studies was not attempted due to the variations in the study design, methodology, study duration, and reporting of the pain response (percentages, VAS scores, or pain categories, etc.).

\section{Method of the Review (Data Collection and Analysis)}

From the titles retrieved in the electronic search all relevant clinical studies and reviews were identified by one of the authors (Belkais Karim [BK]) who then obtained copies of all the relevant studies where available for further consideration. Two reviewers (BK and David Gillam [DG]) determined the quality of the eligible papers and data extraction based on the randomisation procedure, allocation concealment, blinding, and description of any dropouts (withdrawals) [13, 14]. Any differences as to inclusion or exclusion of articles were resolved following discussion between BK and DG. Data extracted from the included and excluded studies was completed on the relevant data extraction forms [13].

Sensitivity from $\mathrm{DH}$ was assessed using the following types of measurements: tactile (pressure with a standardised probe) or thermal (heat/cold) stimulation or evaporative (air blast) stimulation. Patients' subjective assessment was also included in the analysis. Only sensitivity measurements recorded after 6 and 8 weeks were included due to the variability in the length of the published studies. 


\section{Results}

7.1. Overall Description of the Included and Excluded Studies. After the initial screening of identified articles for the present paper, there were 390 potentially relevant studies found either by searching the electronic databases (PUBMED) or by hand searching articles from the literature. Unpublished articles were found both by searching the electronic databases and by hand searching. 94 studies were regarded as relevant for this study while 296 studies were excluded (Figure 1). Following an evaluation of the selected 94 studies, 87 studies were excluded, 32 of these studies were strontium-based toothpaste studies [7, 15-45] (Table 1), and 55 were potassium-based toothpaste studies $[3,9,46-98]$ (Table 2). The reasons for exclusion of these 87 studies are detailed in Tables 1 and 2. 7 strontium- and potassium-based toothpaste studies were included in the present paper [99-105] (Tables 3 and 4). The flow diagram (Figure 1) of the selection procedure is illustrated later.

7 strontium- and potassium-based toothpaste studies therefore fulfilled the criteria for inclusion in the review. In all these studies the experimental toothpaste either contained strontium or potassium whereas the control toothpastes were without strontium or potassium. From the 7 included studies, only 1 article was identified specifically for strontium salts (as the principal (test) toothpaste) and 6 articles were identified specifically for potassium salts (as the principal (test) toothpaste). The description of the 7 included studies is shown in Tables 3 and 4.

\subsection{Analysis of Included Studies}

7.2.1. Study Design. The 7 studies included in the present paper were only from randomised controlled parallel groups blind clinical Trials (RCT). The control toothpastes were either positive (active) [101-103, 105] or negative (placebo) $[99,100,104]$. The blindness was double-blinded [99-105].

7.2.2. Study Population. Most included studies were conducted in either dental practices or university hospitals. The recruited study participants in the included studies were dentate, healthy human adults with a known history of DH. Regarding the gender distribution, most of the included studies enrolled mainly females [99-105]. The total numbers of participants (447) from the 7 included studies were as follows: (1) for the one strontium-based study there were 57 participants and (2) for the six potassium-based studies there were 390 participants, respectively (Tables 3 and 4).

7.2.3. Age Range of Participants. There was variation in the age range distribution(s) in the included studies; however all participants in the included studies were adults (at least 18 years of age). All 7 included studies reported both the age range and the mean age.

7.2.4. Study Duration. The duration of the 7 included studies evaluating the efficacy of strontium- and potassium-based toothpastes/gels in DH was short term (no longer than

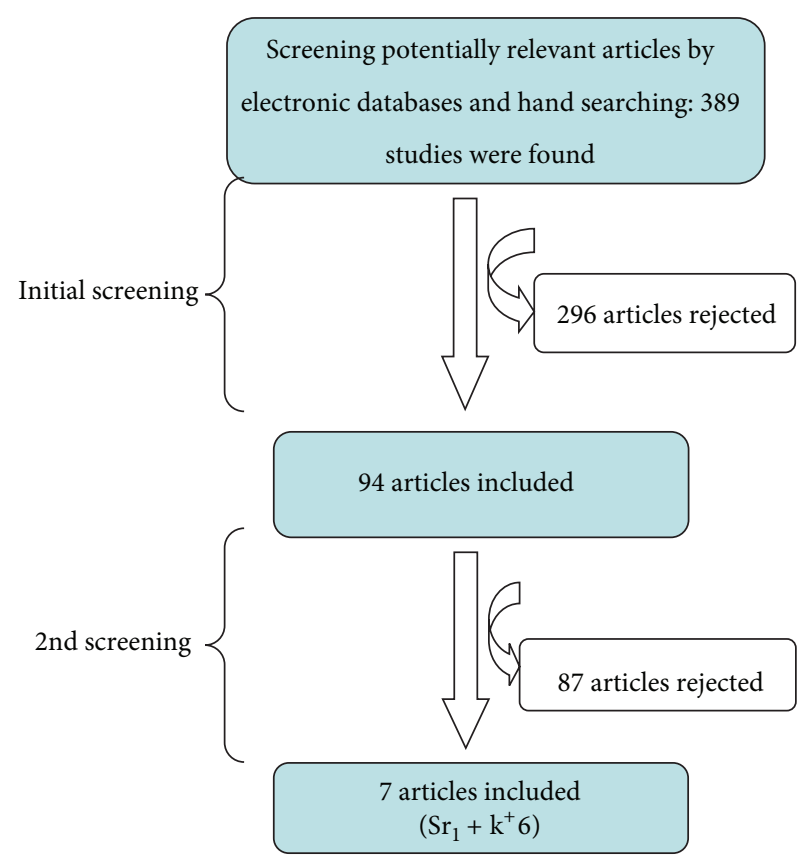

FIGURE 1: Flow diagram of the study selection process.

3 months), ranging from 8 to 12 weeks (Table 5). According to the Poulsen et al. [9] systematic review, only studies that reported sensitivity measurements following 6 and 8 weeks of product use were included in their 2008 review.

7.2.5. Statistics Power Calculation. There were a wide variety of statistical tests used in the included studies. The most commonly used test was "ANOVA" [99, 101-104] (Table 6).

7.2.6. Randomisation and Allocation Concealment (See [13]). According to Schulz [107] random allocation to intervention groups in a clinical study remains the only method of ensuring that the groups being compared are on an equivalent footing at study outset, thus eliminating selection and confounding biases. In most of the 7 included studies the degree of concealment was unclear (random allocation stated/indicated but the actual allocation concealment method is not described or an apparently adequate concealment scheme is reported but there is uncertainty whether allocation is adequately concealed) [100-105]. In the Minkoff and Axelrod [99] strontium study the randomization process was made externally by a statistical department using a computer-generated random table.

7.2.7. Consideration of Withdrawals and Dropouts (See [13]). According to Bowers [108, 109] withdrawals and dropouts that occur following the randomization process may adversely affect the balance of the two groups that had been achieved through the randomization process which may in turn affect any subsequent data analysis (through loss of data). One way of resolving this problem is to include data of these participants as they were still in the study; this is 
TABLE 1: Characteristics of Strontium-based toothpastes excluded studies (reasons).

\begin{tabular}{|c|c|c|}
\hline No. & Study & Reason for exclusion \\
\hline 1 & Addy et al. [15] & Different abrasive concentrations and compounds in the test and comparison toothpastes \\
\hline 2 & Blitzer [16] & The selected participants had developed a general sensitivity during the course of periodontal treatment \\
\hline 3 & Carrasco [17] & Study duration was only 20 days ( $\sim 3$ weeks) \\
\hline 4 & Dabsie et al. [18] & In vitro study \\
\hline 5 & Earl et al. [19] & In vitro study \\
\hline 6 & Gedalia et al. [20] & In vitro study \\
\hline 7 & Gedalia et al. [21] & The use of $\mathrm{SrCl}_{2}$ solution \\
\hline 8 & Gillam et al. [22] & Study reported on the effect of $\mathrm{SrCl}_{2}$ toothpaste on plaque accumulation and gingival inflammation \\
\hline 9 & Gillam et al. [23] & Study reported on the effect of different toothpaste abrasive $\mathrm{DH}$ \\
\hline 10 & ${ }^{*}$ Goldie [24] & Review (2011) \\
\hline 11 & Gutentag [25] & In vitro study \\
\hline 12 & Hughes et al. [26] & Different fluoride concentrations and compounds in the test and comparison toothpastes \\
\hline 13 & *Jackson [7] & Review \\
\hline 14 & *Kanapka [27] & Review \\
\hline 15 & ${ }^{*}$ Kishore et al. [28] & Not clear if the study was randomised \\
\hline 16 & Kobler et al. [29] & $\mathrm{SrCl}_{2}$ solution (varnish) was used \\
\hline 17 & ${ }^{*}$ Markowitz [30] & Review \\
\hline 18 & Mason et al. [31] & Different fluoride concentration in the test and comparison toothpastes \\
\hline 19 & Parkinson et al. [32] & In vitro study \\
\hline 20 & Pearce et al. [33] & Different fluoride concentrations and compounds in the test and comparison toothpastes \\
\hline 21 & ${ }^{*}$ Pol et al. [34] & Unobtainable article (review?) \\
\hline 22 & Ross [35] & No control (placebo/active) group \\
\hline 23 & Shapiro et al. [36] & Abstract only \\
\hline 24 & Shapiro et al. [37] & The outcome measurements were not clear \\
\hline 25 & Stazen and Forman [38] & In vitro study \\
\hline 26 & Surdacka et al. [39] & In vitro study \\
\hline 27 & ${ }^{*}$ Tarbet et al. $[40]$ & Study duration was only 4 weeks \\
\hline 28 & Uchida et al. [41] & Study on the efficacy of $\mathrm{SrCl}_{2}$ in the management of $\mathrm{DH}$ following periodontal surgery \\
\hline 29 & ${ }^{*}$ West $[42]$ & Different fluoride concentrations and compounds in the test and comparison toothpastes \\
\hline 30 & West et al. [43] & Abstract \\
\hline 31 & Collins and Perkins [44] & Different compounds in the test and comparison toothpastes. No strontium-free placebo \\
\hline 32 & Kumar et al. [45] & Different compounds in the test and comparison toothpastes. No strontium-free placebo \\
\hline
\end{tabular}

${ }^{*}$ Studies contain both Strontium and Potassium together.

called intention-to-treat analysis. Withdrawals and dropouts were reported in 4 out of 7 included studies (Table 7).

\section{Data Analysis}

No further analyses were performed on the mean differences from 6 to 8 weeks for any other measurement outcomes for the purpose of meta-analysis.

8.1. Previous History of DH Reported at Baseline. This entails any history of DH in the included studies, reported by investigators, in the form of baseline data, which was confirmed by a response to tactile and/or thermal stimulus.

8.2. Types of Treatment Intervention. In all the 7 included studies a daily home use of strontium- [99] and/or potassium-
[100-105] based toothpastes/gels versus controls (strontiumor potassium-free toothpastes) was the only type of treatment intervention.

8.3. The Clinical Methodology Used to Assess DH. The most commonly reported DH/RS assessment methods by investigators in the 7 included studies were tactile (mainly by using a Yeaple probe), thermal (hot/cold air or water), and evaporative (air blast). Tables 3 and 4 show a summary of the characteristics of the included studies including the assessment methods used for DH. Regarding the subjective assessment of DH, VAS was the main subjective scale used $[101,104]$. The Nagata et al. study [100] used Tarbet's fourpoint air sensitivity scale $[78,106]$. Only three included studies used the Schiff's cold air sensitivity scale [102, 103, 105]. However, two studies used questionnaires $[99,100]$ (Table 8). 
TABLE 2: Characteristics of potassium based toothpastes excluded studies (reasons).

\begin{tabular}{|c|c|c|}
\hline No. & Study & Reason for exclusion \\
\hline 1 & Ajcharanukul et al. [46] & $\mathrm{KCl}$ solution was used \\
\hline 2 & Andreana et al. [47] & Abstract only \\
\hline 3 & Aris et al. [48] & Abstract only \\
\hline 4 & Ayad et al. [49] & $\begin{array}{l}\text { Different fluoride concentrations and compounds in the test and comparison } \\
\text { toothpastes }\end{array}$ \\
\hline 5 & Ayad et al. [50] & $\begin{array}{l}\text { Different fluoride concentrations and compounds in the test and comparison } \\
\text { toothpastes }\end{array}$ \\
\hline 6 & Bohen and Lafont [51] & In-office treatment \\
\hline 7 & Browning et al. [52] & $\begin{array}{l}\text { Study on the safety and efficacy of a night guard bleaching agent containing } \\
\mathrm{NaF} \text { and } \mathrm{KNO}_{3}\end{array}$ \\
\hline 8 & Charig et al. [53] & Abstract only \\
\hline 9 & Conforti et al. [54] & $\begin{array}{l}\text { Study duration: } 14 \text { days ( } 2 \text { weeks) } \\
\text { Different fluoride concentrations and compounds in the test and comparison } \\
\text { toothpastes }\end{array}$ \\
\hline 10 & Cooley and Sandoval [55] & Potassium oxalate solution was used \\
\hline 11 & Docimo et al. [56] & $\begin{array}{l}\text { Different fluoride concentrations and compounds in the test and comparison } \\
\text { toothpastes }\end{array}$ \\
\hline 12 & Frechoso et al. [57] & Study duration was 14 days (2 weeks) \\
\hline 13 & Gillam et al. [58] & $\mathrm{KNO}_{3}$ mouthwash was used \\
\hline 14 & Gillam et al. [59] & $\begin{array}{l}\text { Different fluoride concentrations and compounds in the test and comparison } \\
\text { toothpastes }\end{array}$ \\
\hline 15 & Goncalves et al. [60] & Abstract only \\
\hline 16 & Hall et al. [61] & Abstract only \\
\hline 17 & Van Haywood et al. [62] & Study on the efficacy of $\mathrm{KNO}_{3}-\mathrm{F}$ gel to reduce bleaching sensitivity \\
\hline 18 & Haywood et al. [63] & Study on the efficacy of $\mathrm{KNO}_{3}$ toothpaste to reduce bleaching sensitivity \\
\hline 19 & Hodosh [64] & Review \\
\hline 20 & Hodosh [65] & Not an RCT \\
\hline 21 & Jalalian et al. [66] & $\begin{array}{l}\text { Study on the efficacy of } \mathrm{KNO}_{3} \text { in reduction of hypersensitivity in teeth with } \\
\text { full-crown preparations }\end{array}$ \\
\hline 22 & Kawamata et al. [67] & Abstract only \\
\hline 23 & Lecointre et al. [68] & $\begin{array}{l}\text { Different fluoride concentrations and compounds in the test and comparison } \\
\text { toothpastes. Study duration: } 4 \text { weeks }\end{array}$ \\
\hline 24 & Manochehr-pour et al. [69] & Incomplete data \\
\hline 25 & McCormack and Davies. [70] & Review \\
\hline 26 & Mordan et al. [71] & Abstract only \\
\hline 27 & Morris et al. [72] & Abstract only \\
\hline 28 & Orchardson and Gillam [3] & Review \\
\hline 29 & Pamir et al. [73] & In-office treatment \\
\hline 30 & Peacock and Orchardson [74] & $\begin{array}{l}\text { Animal (rat) study for the effect of }(\mathrm{K}) \text { ions on action potential conduction in } \\
\text { A- and C-fibres }\end{array}$ \\
\hline 31 & Peacock and Orchardson [75] & $\begin{array}{l}\text { Animal (rat) study to assess the ability of some organic }(\mathrm{K}) \text { salts to block } \\
\text { action potential conduction }\end{array}$ \\
\hline 32 & Pereira et al. [76] & In vitro study \\
\hline 33 & Pillon et al. [77] & $\begin{array}{l}\text { Study on the effect of a single application of } 3 \% \text { potassium oxalate gel } \\
\text { immediately after subgingival scaling and root planning on } \mathrm{DH}\end{array}$ \\
\hline 34 & Pol et al. [78] & Review \\
\hline 35 & Poulsen et al. [9] & Review \\
\hline 36 & Prasad et al. [79] & $\begin{array}{l}\text { Different fluoride concentrations and compounds in the test and comparison } \\
\text { toothpastes }\end{array}$ \\
\hline 37 & Reinhart et al. [80] & A pilot study \\
\hline 38 & Salian et al. [81] & Study duration: 4 weeks \\
\hline
\end{tabular}


TABLE 2: Continued.

\begin{tabular}{|c|c|c|}
\hline No. & Study & Reason for exclusion \\
\hline 39 & Salvato et al. [82] & $\begin{array}{l}\text { Different fluoride concentrations and compounds in the test and comparison } \\
\text { toothpastes }\end{array}$ \\
\hline 40 & Sharma $[83]^{*}$ & No data available at 6 to 8 weeks \\
\hline 41 & Sharma et al. [84] & No data available at 6 to 8 weeks \\
\hline 42 & Silverman $[85]$ & Test and control toothpastes were not clearly detailed \\
\hline 43 & Silverman et al. [86] & Incomplete data \\
\hline 44 & Sowinski et al. [87] & $\begin{array}{l}\text { No potassium-free comparison group; different fluoride concentrations and } \\
\text { compounds in the test and comparison groups }\end{array}$ \\
\hline 45 & Sowinski et al. [88] & $\begin{array}{l}\text { Different fluoride concentrations and compounds in the test and comparison } \\
\text { toothpastes }\end{array}$ \\
\hline 46 & Stead et al. [89] & Review (mathematical model) \\
\hline 47 & Tarbet et al. [90] & Not clear if the study was randomized. Study duration: 4 weeks \\
\hline 48 & Tarbet et al. [91] & $\begin{array}{l}\text { Study on the pulpal effects of brushing with a }\left(5 \% \mathrm{KNO}_{3}\right) \text { paste used for } \\
\text { desensitization }\end{array}$ \\
\hline 49 & Touyz and Stern [92] & $\mathrm{KNO}_{3}$ solution was used to reduce $\mathrm{DH}$ after periodontal surgery \\
\hline 50 & Wang et al. [93] & Abstract only \\
\hline 51 & Wara-aswapati et al. [94] & No data available at 6 to 8 weeks \\
\hline 52 & Yates et al. [95] & Potassium citrate-containing mouth rinse was used \\
\hline 53 & Yates et al. [96] & No potassium-free comparison group \\
\hline 54 & Orsini et al. [97] & $\begin{array}{l}\text { Different fluoride concentrations and compounds in the test and comparison } \\
\text { toothpastes }\end{array}$ \\
\hline 55 & Pradeep and Sharma [98] & $\begin{array}{l}\text { Different compounds in the test and comparison toothpastes. Calcium } \\
\text { sodium phosphosilicate was evaluated against a potassium nitrate and placebo } \\
\text { with no calcium sodium phosphosilicate }\end{array}$ \\
\hline
\end{tabular}

${ }^{*} \mathrm{http}: / /$ www.oralscience.ca/. A randomized parallel group clinical study accessed 2010.

TABLE 3: Characteristics of the included Strontium containing toothpaste studies.

\begin{tabular}{ccccccc}
\hline No. & Study & Methods & Participants & Interventions & Outcomes & Results \\
\hline & $\begin{array}{c}\text { Minkoff and } \\
\text { Axelrod } \\
{[99]^{*}}\end{array}$ & $\begin{array}{c}12 \text { weeks, parallel, } \\
\text { double-blind, } \\
\text { randomised }\end{array}$ & $\begin{array}{c}57 \text { completing } \\
\text { out of } 61\end{array}$ & $\begin{array}{c}10 \% \mathrm{SrCl}_{2} \\
\text { versus } 0 \% \mathrm{SrCl}_{2}\end{array}$ & $\begin{array}{c}\text { Tactile and } \\
\text { thermal }\end{array}$ & $\begin{array}{c}\mathrm{SrCl}_{2}>\text { placebo control }(P<0.05) \text { after } 4 \text { weeks } \\
\text { (subjective), after 8 weeks (air blast), and at 12 weeks } \\
\text { (tactile) }\end{array}$ \\
\hline
\end{tabular}

${ }^{*}$ Formulation was subsequently changed from an $\mathrm{SrCl}_{2}$ with diatomaceous earth to $\mathrm{SrCl}_{2}$ with a silica abrasive/filler. A Strontium chloride toothpaste is no longer available in some markets. A Strontium acetate with fluoride toothpaste is currently available.

8.4. Calibration and Examiner Training. There was no reported training or calibration for $\mathrm{DH}$, in either the examination or assessment techniques prior to the commencement of the study, in any of the included studies.

8.5. Measurement of Compliance. There was no reported measurement of patient compliance, for example, diaries, weighing of toothpastes, or log books in any of the included studies.

\section{Discussion}

It is evident from the published literature that $\mathrm{DH}$ is not only a troublesome condition for dental professionals to effectively diagnose and manage but it may also have a profound effect on the quality of life of those who suffer with the problem [110-112]. Currently there is a plethora of remedies available for both OTC and in-office applications; however it is evident that none of these products appear to provide an effective long-lasting solution to the problem $[1,3]$. Most of these products either work on the basis of their tubular occluding properties, for example, strontium-based (chloride and acetate) products, or by nerve desensitization, for example, potassium-based (chloride, citrate, and nitrate) products. Evidence for their efficacy however has been questioned by several investigators in a series of reviews over the last decade [7-11, 113].

The aim of the present paper was to evaluate the efficacy of both strontium and potassium toothpastes based on the published systematic review methodology of Poulsen et al. [9]; however the authors concede that the present paper may have been too restrictive in considering only studies with matched placebo controls. It may therefore be argued that the inclusion of studies with a valid negative control, such as a commercially available fluoride toothpaste, may have given a better indication of whether a toothpaste containing 
Table 4: Characteristics of Potassium containing toothpastes included studies.

\begin{tabular}{|c|c|c|c|c|c|c|}
\hline No. & Study & Methods & Participants & Interventions & Outcomes & Results \\
\hline 1 & $\begin{array}{l}\text { Nagata et al. } \\
{[100]}\end{array}$ & $\begin{array}{l}12 \text { weeks, parallel, } \\
\text { double-blind, } \\
\text { randomised }\end{array}$ & $\begin{array}{l}36 \text { completing } \\
\text { out of } 36\end{array}$ & $5 \% \mathrm{KNO}_{3}$ versus $0 \% \mathrm{KNO}_{3}$ & $\begin{array}{l}\text { Tactile, air blast, } \\
\text { and subjective }\end{array}$ & $\begin{array}{l}5 \% \text { KNO3 }>\text { control }(P, \\
0.05) \text { at } 4,8 \text {, and } 12 \text { weeks }\end{array}$ \\
\hline 2 & $\begin{array}{l}\text { Schiff et al. } \\
\quad[101]\end{array}$ & $\begin{array}{l}12 \text { weeks, parallel, } \\
\text { double-blind, } \\
\text { randomised }\end{array}$ & $\begin{array}{l}58 \text { completing } \\
\text { out of } 67\end{array}$ & $\begin{array}{c}5 \% \mathrm{KNO}_{3} \text { and } 0.243 \% \\
\text { sodium } \mathrm{MFP} \text { versus } 0 \% \\
\mathrm{KNO}_{3} \text { and } 0.243 \% \text { sodium } \\
\mathrm{MFP}\end{array}$ & $\begin{array}{l}\text { Thermal, tactile, air } \\
\text { blast, and } \\
\text { subjective }\end{array}$ & $\begin{array}{c}\text { Test }>\text { control }(P<0.01) \text { at } \\
6 \text { and } 12 \text { weeks }\end{array}$ \\
\hline 3 & $\begin{array}{l}\text { Schiff et al. } \\
\quad[102]\end{array}$ & $\begin{array}{l}8 \text { weeks, parallel, } \\
\text { double-blind, } \\
\text { randomised }\end{array}$ & $\begin{array}{l}39 \text { completing } \\
\text { out of } 48\end{array}$ & $\begin{array}{c}5 \% \mathrm{KNO}_{3} \text { and } 1500 \mathrm{ppm} \\
\mathrm{MFP} \text { versus } 0 \% \mathrm{KNO}_{3} \text { and } \\
1500 \mathrm{ppm} \mathrm{MFP}\end{array}$ & Tactile and air blast & $\begin{array}{c}5 \% \mathrm{KNO} 3>\text { control }(P< \\
0.0001) \text { at } 4 \text { and } 8 \text { weeks }\end{array}$ \\
\hline 4 & $\begin{array}{l}\text { Schiff et al. } \\
\quad[103]\end{array}$ & $\begin{array}{l}8 \text { weeks, parallel, } \\
\text { double-blind, } \\
\text { randomised }\end{array}$ & 80 participants & $\begin{array}{c}5 \% \mathrm{KNO}_{3} \text { and } 0.243 \% \mathrm{NaF} \\
\text { versus } 0.243 \% \mathrm{NaF}\end{array}$ & Tactile and air blast & $\begin{array}{c}5 \% \mathrm{KNO} 3>\text { positive and } \\
\text { negative controls }(P<0.05) \\
\text { in tactile and air blast } \\
\text { sensitivity, at } 4 \text { and } 8 \text { weeks }\end{array}$ \\
\hline 5 & $\begin{array}{l}\text { Silverman et al. } \\
{[104]}\end{array}$ & $\begin{array}{l}8 \text { weeks, parallel, } \\
\text { double-blind, } \\
\text { randomised }\end{array}$ & 110 completing & $5 \% \mathrm{KNO}_{3}$ versus $0 \% \mathrm{KNO}_{3}$ & $\begin{array}{l}\text { Tactile, cold air, } \\
\text { and subjective }\end{array}$ & $\begin{array}{c}5 \% \mathrm{KNO} 3>+/-\mathrm{F}>\mathrm{F} \\
\text { control at } 4 \text { and } 8 \text { weeks }(P \\
<0.02) \text {; NS between } 10 \% \mathrm{Sr} \\
\mathrm{Cl} 2 \text { and control; } 5 \% \mathrm{KNO} 3 \\
>+/-\mathrm{F}>10 \% \mathrm{Sr} \mathrm{Cl} 2 \text { at } 8 \\
\text { weeks }(P<0.05)\end{array}$ \\
\hline 6 & $\begin{array}{l}\text { Sowinski et al. } \\
{[105]^{*}}\end{array}$ & $\begin{array}{l}8 \text { weeks, parallel, } \\
\text { double-blind, } \\
\text { randomised }\end{array}$ & 67 completing & $\begin{array}{c}5 \% \mathrm{KNO}_{3} \text { and } 0.243 \% \mathrm{NaF} \\
\text { versus } 0.243 \% \mathrm{NaF}\end{array}$ & Tactile and air blast & $\begin{array}{l}\mathrm{KNO}_{3}>\text { control significant } \\
\text { improvements in tactile and } \\
\text { air blast at } 4 \text { and } 8 \text { weeks }\end{array}$ \\
\hline
\end{tabular}

* Product withdrawn from the market.

TABLE 5: Study duration of included studies.

\begin{tabular}{lc}
\hline Study & Study duration \\
\hline Minkoff and Axelrod [99] & 12 weeks \\
Nagata et al. [100] & 12 weeks \\
Schiff et al. [101] & 12 weeks \\
Pradeep and Sharma [98] & 8 weeks \\
Schiff et al. [102] & 8 weeks \\
Schiff et al. [103] & 8 weeks \\
Sowinski et al. [105] & 8 weeks \\
\hline
\end{tabular}

TABLE 6: Statistical tests used in the included studies.

\begin{tabular}{lc}
\hline Study & Statistical test \\
\hline Minkoff and Axelrod [99] & $\begin{array}{c}\text { ANOVA, } t \text {-test, Spearman's rank } \\
\text { correlation coefficient } \\
\text { Mann-Whitney } U \text { test }\end{array}$ \\
Nagata et al. [100] & Chi-square/Fisher's exact probability \\
& test \\
Schiff et al. [101-103] & ANOVA \\
Silverman et al. [104] & ANOSt \\
Sowinski et al. [105] & $t$-test \\
\hline
\end{tabular}

the active ingredient could deliver the desired efficacy (e.g., a reduction in sensitivity). The rationale however for conducting the present paper was to determine whether the active ingredient in toothpaste delivers efficacy in the reduction of $\mathrm{DH}$ which is the basis of the claims made for these toothpastes by the manufacturers. Other benefits that have been attributed to these toothpastes such as antiplaque and anticaries benefits have not been considered in the present paper. Generally speaking these benefits are often "based on the results of previous caries studies or plaque studies and there is very little evidence from the published literature on desensitising toothpastes that these ingredients have been shown to demonstrate these benefits" $[22,23,65]$.

For the purpose of the present paper, studies (e.g., randomized controlled clinical trials) were included in which strontium and/or potassium-containing toothpastes/gels were compared to nonpotassium and/or nonstrontium toothpastes. The type of intervention examined was the daily home use of strontium and/or potassium-containing toothpastes/gels versus control toothpastes/gels. In each study the toothpastes were either both containing fluoride or having no fluoride and the control toothpaste was exactly the same as the test toothpaste apart from the addition of either a strontium (acetate or chloride) or potassium (citrate, chloride, and citrate) salt. It should be noted that currently most strontium-based toothpastes contain an acetate variant rather than the chloride variant and potassium-based toothpastes contain a nitrate variant depending on the particular commercial market.

Following an initial screening of the available publications there were a total of 87 excluded studies following the final filtration of 94 studies (Tables 1 and 2 and Figure 1). The reasons for excluding 32 strontium studies were either due to the different fluoride or abrasive concentrations and compounds in both test and comparison toothpastes [26, $31,33,42,114]$. Two studies were excluded as they were 
TABLE 7: Number of dropout participants from the included studies and the reasons for dropout (4 studies).

\begin{tabular}{lcc}
\hline Study & No. of dropouts & Reason(s) for dropping out \\
\hline Minkoff and Axelrod [99] & 4 out of 61 & 3 had minor side effects upon use of active product \\
Schiff et al. [101] & 9 out of 67 & For personal reasons \\
Schiff et al. [102] & 9 out of 48 & For reasons unrelated to dentifrice use \\
Sowinski et al. [105] & All participants completed to dentifrice use
\end{tabular}

TABLE 8: The different types of DH assessment used in the included studies.

\begin{tabular}{lcc}
\hline Study & DH assessment method(s) & Subjective assessment \\
\hline Minkoff and Axelrod [99] & Tactile and thermal & Questionnaire \\
Nagata et al. [100] & Tactile and air blast & Tarbet's scale and questionnaire [106] \\
Schiff et al. [101] & Tactile, air blast, and thermodontic stimulator (thermal) & VAS \\
Schiff et al. [102, 103] & Tactile and air blast & Schiff's sensitivity scale (0-3) \\
Silverman et al. [104] & Tactile and air blast & VAS \\
Sowinski et al. [105] & Tactile and air blast & Schiff's sensitivity scale (0-3) \\
\hline
\end{tabular}

related to $\mathrm{DH}$ following periodontal treatment (nonsurgical or surgical studies) [16,41]. A further two studies were excluded due to the short study duration $<6$ weeks $[17,40]$. A further seven studies were also excluded as they were in vitro studies [18-20, 25, 32, 38, 39]. Two studies were also excluded since only $\mathrm{Sr} \mathrm{Cl}_{2}$ solutions/varnishes were used [21, 29]. The Gillam et al. 1992 studies [22, 23] were also excluded as these investigators reported on (1) the effects of $\mathrm{Sr} \mathrm{Cl}_{2}$ toothpaste on plaque accumulation and/or gingival recession and (2) the effect of different toothpaste abrasives in the test and control toothpastes. One study by Shapiro et al. [36] was excluded as it was a reported abstract article and a further study by Shapiro et al. [37] was also excluded due to the lack of clarity in the reported outcome measures. Two further studies were also excluded due to (1) the lack of randomisation procedures [28] and (2) the lack of a control group [35]. Several review articles were also excluded [7, 24, 27]. Two further studies by Collins and Perkins [44] and Kumar et al. [45] were subsequently excluded by one of the authors (DGG) after the initial filtration of included studies as it was apparent that there were different compounds in the test and comparison toothpastes and no strontium-free control. In summary, 32 strontium-related studies were excluded (Table 1) and only 1 study was included in the present paper (Table 3 ). The reasons for the exclusion of the 55 potassium-based toothpaste studies were mainly due to the different fluoride concentrations and/or ingredient(s) in the test and comparison toothpastes $[49,50,54,56,68,79,82,88,97]$ (Table 2). For example, three studies were excluded since the main aim of these studies was to evaluate the efficacy of $\mathrm{KNO}_{3}$ toothpaste/gel in reducing bleaching sensitivity during or following tooth whitening/bleaching procedures $[52,62,63]$. Five studies were also excluded due to the short study duration of the study (<6 weeks) $[54,57,68,81,90]$. A further three studies were excluded as these studies were either in-office $[51,73]$ or in vitro studies [76]. Five studies were also excluded as potassium-containing solutions/mouthwashes were used [46, $55,58,92,95]$. The Jalalian et al. [66] study was also excluded since this was a study evaluating the efficacy of an $\mathrm{KNO}_{3}$ application in reducing $\mathrm{DH}$ with full-crown preparations. The study by Pillon et al. [77] was also excluded since the study was based on the results of a single application of $3 \%$ potassium oxalate gel immediately following scaling and root planning procedures (SRP). The Tarbet et al. [91] study was also excluded as this study only evaluated the pulpal effect following brushing with a $5 \% \mathrm{KNO}_{3}$ toothpaste. A further nine studies were excluded since these studies were reported in an abstract [47, 48, 53, 60, 61, 67, 71, 72, 93]. A review by Hodosh [64] was also excluded as well as a non-RCT study reported by the same investigator [65]. A study by Manochehr-Pour et al. [69] was also excluded due to incomplete data reported in the study. The two animal studies by Peacock and Orchardson $[74,75]$ were also excluded and a pilot study reported by Reinhart et al. [80] was excluded. The studies by Sharma [83], Sharma et al. [84], and Wara-aswapati et al. [94] were also excluded as no data was available at the 6to-8-week time intervals. Two studies by Silverman [85] and Silverman et al. [86] were excluded either because (1) the test and control toothpastes were not clearly detailed or (2) due to incomplete data recorded in the study. In the Yates et al. [96] study there was no potassium-free comparison group included in the design of the study. The study by Stead et al. [89] was excluded as this was a review paper. Other reviews, by other investigators [24, 70, 78], were also excluded from this paper. A further study by Pradeep and Sharma [98] was subsequently excluded by one of the authors (DGG) as it was apparent that there were different compounds in the test and comparison toothpastes and no potassium-free control. In this study a calcium sodium phosphosilicate toothpaste was evaluated against a positive control potassium nitrate and a placebo without calcium sodium phosphosilicate. In summary, 55 potassium-based toothpaste studies were excluded and the reasons for exclusion were described in Table 2 .

The results from the present paper were therefore based on the 7 included studies (1 strontium-based and 
6 potassium-based toothpastes) and in context would appear to support conclusions from the previous reviews that there were measurable positive reductions in $\mathrm{DH}$ from baseline values. Although the present review did not include metaanalysis of the published data from these studies for the reasons outlined earlier in the paper, the results from the Poulsen et al. study [9] and the present paper were based on 6 potassium toothpaste studies. The results indicated that these differences were in favour of the treatment group for both "air" and "tactile" measurements but not for the "subjective" measurements. Generally speaking interpreting air, tactile, and subjective elements in DH studies is fraught with difficulties $[4,115]$. For example, most studies demonstrate that the placebo group would provide significant improvements in percentage terms as well as the test group and as such any significance between the groups may be masked [7, 42]. The variation in the methodology employed by different examiners (Table 8) may also have an impact on the efficacy of a toothpaste as well as the highly subjective nature of the pain response between individuals [9]. Some investigators in the present paper used a Yeaple or an explorer probe or a thermal probe versus a cold air blast or assessed the subjective assessment using either a visual analogue scale (VAS) or a Schiff scale [101-105] or questionnaires [99, 100, 106] (Tables 4 and 8). An observation when evaluating the methodology reported in the included studies was that there was no reporting of any training or calibration of the investigators prior to the commencement of the studies. Although a number of these investigators (e.g., Schiff [101103] were experienced assessors in DH evaluation studies it was impossible to determine whether the investigators were consistent in the assessments during the study. It should be noted however that the variability of these subjective pain outcomes is difficult to control even when using objective measures [4].

One of the problems encountered when conducting the present paper was that there was considerable variation with the manner in the studies were designed and conducted, for example, factors such as the duration, variation in sample size, methodology used to assess the products as well as differences in the test, placebo and control toothpastes and the impact of the placebo and non-placebo improvements in the control toothpastes, makes it difficult to make exact comparisons from the results of these studies (Tables 38) $[7,9,11]$. There is no doubt that there is a degree of accommodation and awareness of the pain response by individuals during a study as well as confounding variables such as placebo and nonplacebo effects regression to the mean or mode that may subsequently influence the study outcomes. For example, Curro et al. [116] reporting on a series of $\mathrm{DH}$ product evaluation studies indicated that there were a number of false positives associated with tactile assessment when using the Yeaple probe particularly at the lower range of pressures. These investigators also highlighted that the range of the placebo effect observed in DH studies is similar to that observed in both medical and pharmaceutical studies.

One of the problems encountered when analysing data from the published literature on the efficacy of strontium and potassium-based toothpastes was that due to the strict inclusion/exclusion criteria based on Poulsen et al. [9] in the present paper none of the included studies made a direct comparison between the two products (Tables 3 and 4). This was a concern and the authors were therefore unable to comment on a direct comparison between the two products and as such may limit the conclusions that could be made regarding the two products. From the published literature it was evident that earlier studies did provide direct comparisons of these products although as Cummins [11] suggested in her review that prior to 1997 there was considerably more variations in the design and conduct of DH studies as well as the ingredients of the toothpastes per se. This again may confound any meaningful conclusions when comparing results from these $\mathrm{DH}$ evaluation studies. It should be noted however that published studies (after 1997) would appear to follow a similar design and conduct based on the Holland [5] and/or ADA [6] guidelines when assessing various desensitising products. Several investigators have however questioned the validity and reproducibility of some of these techniques for evaluating DH products $[4,115]$.

The results from the limited number of included strontium-based studies in the present paper would therefore limit any conclusions that may be drawn from the studies (Table 3), even though there is some evidence of their efficacy in a strontium chloride product $[17,21-23,29,41]$ or a strontium acetate product $[26,31,33,42,43,59]$. A number of investigators have also reviewed the efficacy of strontium-based toothpastes [7, 10, 30, 113]. Jackson [7] however indicated in his review that none of the studies on strontium toothpastes demonstrated a consistent, significant improvement in the participants' symptoms of $\mathrm{DH}$ when compared with the negative control toothpaste. There also appears to be no supportive evidence from the published literature for strontium salts enhancing the deposition of the ingredients of the toothpaste or increasing the durability of the deposit on the tooth surface [7].

One of the aims of the present review was to update the previous review of Poulsen et al. [9]; however no subsequently published studies (up to 2010) were considered to be suitable for inclusion and as a result no further information on the efficacy of potassium-based toothpastes was forthcoming. A number of investigators have also raised concerns with regard to the efficacy of potassium-based toothpastes and this has led to the suggestion that potassium-based toothpastes may be no more effective than regular fluoride toothpaste $[7,8$, 10]. The lack of data on the efficacy of potassium-containing toothpastes in reducing $\mathrm{DH}$ has also been highlighted in a recent systematic review by Pol et al. [78].

No conclusions however can be made from the present paper on the direct comparison of the efficacy of strontium and potassium-based toothpastes in reducing $\mathrm{DH}$. This was due to the limitation of any of the included studies making a direct comparison between the two toothpastes although a number of excluded studies did make such a comparison.

\section{Conclusions}

Although both strontium and potassium-based toothpastes have been demonstrated to provide a reduction in clinical 
symptoms of $\mathrm{DH}$ in previously published clinical studies, the conclusions from the present systematic review would suggest that there is insufficient evidence to state categorically whether strontium or potassium salts per se are effective in reducing $\mathrm{DH}$.

\section{Acknowledgment}

The authors acknowledge the valuable contribution of Dr. Valeria Marinho for her advice on conducting a systematic review.

\section{References}

[1] Canadian Advisory Board on Dentin Hypersensitivity, "Consensus-based recommendations for the diagnosis and management of dentin hypersensitivity," Journal of the Canadian Dental Association, vol. 69, no. 4, pp. 221-226, 2003.

[2] D. G. Gillam, "Current diagnosis of dentin hypersensitivity in the dental office: an overview," Clinical Oral Investigations, 2013.

[3] R. Orchardson and D. G. Gillam, "Managing dentin hypersensitivity," Journal of the American Dental Association, vol. 137, no. 7, pp. 990-998, 2006.

[4] D. G. Gillam and H. N. Newman, "Assessment of pain in cervical dentinal sensitivity studies. A review," Journal of Clinical Periodontology, vol. 20, no. 6, pp. 383-394, 1993.

[5] G. R. Holland, "Guidelines for the design and conduct of clinical trials on dentine hypersensitivity," Journal of Clinical Periodontology, vol. 24, no. 11, pp. 808-813, 1997.

[6] "ADA Acceptance Program Guidelines-Products for the Treatment of Dentinal Hypersensitivity," 2009, http://www. docstoc.com/docs/ 2976618/ Acceptance-Program-GuidelinesProducts-for-the-Treatment-of-Dentinal-Hypersensitivity.

[7] R. J. Jackson, "Potential treatment modalities for dentine hypersensitivity: home use products," in Tooth Wear and Sensitivity, M. Addy, G. Embery, W. M. Edgar, and R. Orchardson, Eds., pp. 328-338, Martin Dunitz, London, UK, 2000.

[8] R. Orchardson and D. G. Gillam, "The efficacy of potassium salts as agents for treating dentin hypersensitivity," Journal of Orofacial Pain, vol. 14, no. 1, pp. 9-19, 2000.

[9] S. Poulsen, M. Errboe, Y. Lescay Mevil, and A. M. Glenny, "Potassium containing toothpastes for dentine hypersensitivity," in The Cochrane Library, no. 4, 2008.

[10] D. Cummins, "Dentin hypersensitivity: from diagnosis to a breakthrough therapy for everyday sensitivity relief," Journal of Clinical Dentistry, vol. 20, no. 1, pp. 1-9, 2009.

[11] D. Cummins, "Recent advances in dentin hypersensitivity: clinically proven treatments for instant and lasting sensitivity relief," American Journal of Dentistry, vol. 23, pp. 3A-13A, 2010.

[12] D. C. Greenspan, "NovaMinand tooth sensitivity-an overview," Journal of Clinical Dentistry, vol. 21, no. 3, pp. 61-65, 2010.

[13] Y. Hsui, The prevalence of root sensitivity following periodontal therapy: a systematic review [MClinDent Thesis], London, UK, 2010.

[14] J. P. T. Higgins and S. Green, Cochrane Handbook for Systematic Reviews of Intervention 4. 2. 6, 2006.

[15] M. Addy, P. Mostafa, and R. Newcombe, "Dentine hypersensitivity: a comparison of five toothpastes used during a 6-week treatment period," British Dental Journal, vol. 163, no. 2, pp. 4551, 1987.
[16] B. Blitzer, "A consideration of the possible causes of dental hypersensitivity: treatment by a strontium-ion dentifrice," Periodontics, vol. 5, no. 6, pp. 318-321, 1967.

[17] H. P. Carrasco, "Strontium chloride toothpaste-effectiveness as related to duration of use," Pharmacology and Therapeutics in Dentistry, vol. 1, no. 4, pp. 209-215, 1971.

[18] F. Dabsie, G. Gregoire, M. Sixou, and P. Sharrock, "Does strontium play a role in the cariostatic activity of glass ionomer?. Strontium diffusion and antibacterial activity," Journal of Dentistry, vol. 37, no. 7, pp. 554-559, 2009.

[19] J. S. Earl, M. B. Ward, and R. M. Langford, "Investigation of dentinal tubule occlusion using FIB-SEM milling and EDX," Journal of Clinical Dentistry, vol. 21, no. 2, pp. 37-41, 2010.

[20] I. Gedalia, D. Almog, and S. Yariv, "Effects of strontium and fluoride uptakes on the solubility of powdered enamel," Caries Research, vol. 11, no. 5, pp. 287-292, 1977.

[21] I. Gedalia, L. Brayer, and N. Kalter, "The effect of fluoride and strontium application on dentin: in vivo and in vitro studies," Journal of Periodontology, vol. 49, no. 5, pp. 269-272, 1978.

[22] D. G. Gillam, H. N. Newman, E. H. Davies, and J. S. Bulman, "Clinical efficacy of a low abrasive dentifrice for the relief of cervical dentinal hypersensitivity," Journal of Clinical Periodontology, vol. 19, no. 3, pp. 197-201, 1992.

[23] D. G. Gillam, H. N. Newman, J. S. Bulman, and E. H. Davies, "Dentifrice abrasivity and cervical dentinal hypersensitivity. Results 12 weeks following cessation of 8 weeks' supervised use," Journal of Periodontology, vol. 63, no. 1, pp. 7-12, 1992.

[24] M. P. Goldie, "Potassium nitrate, sodium fluoride, strontium chloride, and NovaMin technologies for dentin hypersensitivity," Minimal Intervention Dentistry, vol. 5, no. 4, 2011.

[25] H. Gutentag, "The effect of strontium chloride on peripheral nerve in comparison to the action of "stabilizer" and "labilizer" compounds," The Penn Dental Journal, vol. 68, no. 2, pp. 37-43, 1965.

[26] N. Hughes, S. Mason, P. Jeffery et al., "A comparative clinical study investigating the efficacy of a test dentifrice containing $8 \%$ strontium acetate and $1040 \mathrm{ppm}$ sodium fluoride versus a marketed control dentifrice containing $8 \%$ arginine, calcium carbonate, and $1450 \mathrm{ppm}$ sodium monofluorophosphate in reducing dentinal hypersensitivity," Journal of Clinical Dentistry, vol. 21, no. 2, pp. 49-55, 2010.

[27] J. A. Kanapka, "Over-the-counter dentifrices in the treatment of tooth hypersensitivity. Review of clinical studies," Dental Clinics of North America, vol. 34, no. 3, pp. 545-560, 1990.

[28] A. Kishore, K. K. Mehrotra, and C. S. Saimbi, "Effectiveness of desensitizing agents," Journal of Endodontics, vol. 28, no. 1, pp. 34-35, 2002.

[29] A. Kobler, O. Kuß, H. G. Schaller, and C. R. Gernhardt, "Clinical effectiveness of a strontium chloride-containing desensitizing agent over 6 months: a randomized, double-blind, placebocontrolled study," Quintessence International, vol. 39, no. 4, pp. 321-325, 2008.

[30] K. Markowitz, "The original desensitizers: strontium and potassium salts," Journal of Clinical Dentistry, vol. 20, no. 5, pp. 145151, 2009.

[31] S. Mason, N. Hughes, F. Sufi et al., "A comparative clinical study investigating the efficacy of a dentifrice containing $8 \%$ strontium acetate and $1040 \mathrm{ppm}$ fluoride in a silica base and a control dentifrice containing $1450 \mathrm{ppm}$ fluoride in a silica base to provide immediate relief of dentin hypersensitivity," Journal of Clinical Dentistry, vol. 21, no. 2, pp. 42-48, 2010. 
[32] C. R. Parkinson, A. Butler, and R. J. Willson, "Development of an acid challenge-based in vitro dentin disc occlusion model," Journal of Clinical Dentistry, vol. 21, no. 2, pp. 31-36, 2010.

[33] N. X. Pearce, M. Addy, and R. G. Newcombe, "Dentine hypersensitivity: a clinical trial to compare 2 strontium densensitizing toothpastes with a conventional fluoride toothpaste," Journal of Periodontology, vol. 65, no. 2, pp. 113-119, 1994.

[34] D. G. Pol, J. Jonnala, M. Chute, T. Gunjikar, and S. Pol, "Desensitising agents, "what is more preferable...dentifrice or mouthwash?'”' Journal of the Indian Dental Association, vol. 4, no. 22, pp. 486-487, 2010.

[35] M. R. Ross, "Hypersensitive teeth: effect of strontium chloride in a compatible dentifrice," Journal of Periodontology, vol. 32, pp. 49-53, 1961.

[36] W. B. Shapiro, R. S. Kaslick, and A. I. Chasens, "The effect of a strontiumhloridetoothpaste on root hypersensitivity in a controlled clinical study," Journal of Periodontology, vol. 41, no. 12, pp. 702-703, 1970.

[37] W. B. Shapiro, R. S. Kaslick, A. I. Chasens, and D. Weinstein, "Controlled clinical comparison between a strontium chloride and a sodium monofluorophosphate toothpaste in diminishing root hypersensitivity," Journal of Periodontology, vol. 41, no. 9, pp. 523-525, 1970.

[38] P. J. Stazen and D. W. Foreman, "Diffusion of strontium from desensitizing agents into human dentin as determined by energy-dispersive analysis," Journal of Dental Research, vol. 56, no. 1, pp. 28-35, 1977.

[39] A. Surdacka, J. Stopa, and L. Torlinski, "In situ effect of strontium toothpaste on artificially decalcified human enamel," Biological Trace Element Research, vol. 116, no. 2, pp. 147-153, 2007.

[40] W. J. Tarbet, G. Silverman, P. A. Fratarcangelo, and J. A. Kanapka, "Home treatment for dentinal hypersensitivity: a comparative study," The Journal of the American Dental Association, vol. 105, no. 2, pp. 227-230, 1982.

[41] A. Uchida, Y. Wakano, and O. Fukuyama, "Controlled clinical evaluation of a $10 \%$ strontium chloride dentifrice in treatment of dentin hypersensitivity following periodontal surgery," Journal of Periodontology, vol. 51, no. 10, pp. 578-581, 1980.

[42] N. X. West, "Dentine hypersensitivity and the placebo response A comparison of the effect of strontium acetate, potassium nitrate and fluoride toothpastes," Journal of Clinical Periodontology, vol. 24, no. 4, pp. 209-215, 1997.

[43] N. X. West, M. Addy, R. J. Jackson, and D. B. Ridge, "Comparison of strontium acetate and potassium nitrate dentifrices on dentine hypersensitivity," Journal of Dental Research, vol. 75, 1150, Abstract no. 161, 1996.

[44] J. F. Collins and L. Perkins, "Clinical evaluation of the effectiveness of three dentifrices in relieving dentin sensitivity," Journal of Periodontology, vol. 55, no. 12, pp. 720-725, 1984.

[45] R. V. Kumar, N. Shubhashini, H. Sheshan, and K. Kranti, "A clinical trial comparing a stannous fluoride based dentifrice and a strontium chloride based dentifrice in alleviating dentinal hypersensitivity," Journal of International Oral Heath, vol. 2, pp. 37-50, 2010.

[46] O. Ajcharanukul, P. Kraivaphan, S. Wanachantararak, N. Vongsavan, and B. Matthews, "Effects of potassium ions on dentine sensitivity in man," Archives of Oral Biology, vol. 52, no. 7, pp. 632-639, 2007.

[47] S. Andreana, S. Zanna, B. De Carlo et al., "Dentin permeability after Zinc-carbonate-hydroxyapatite paste treatment: in vitro evaluation," Journal of Dental Research, vol. 87, Abstract no. 1887, 2009.
[48] A. Aris, D. Gillam, H. N. Newman et al., "Assessment of the tactile response in an 8 week hypersensitivity study," Journal of Dental Research, vol. 79, 576, Abstract no. 3459, 2000.

[49] F. Ayad, N. Ayad, Y. P. Zhang, W. DeVizio, D. Cummins, and L. R. Mateo, "Comparing the efficacy in reducing dentin hypersensitivity of a new toothpaste containing $8.0 \%$ arginine, calcium carbonate, and $1450 \mathrm{ppm}$ fluoride to a commercial sensitive toothpaste containing $2 \%$ potassium ion: an eightweek clinical study on Canadian adults," Journal of Clinical Dentistry, vol. 20, no. 1, pp. 10-16, 2009.

[50] F. Ayad, R. Berta, W. De Vizio, J. McCool, M. E. Petrone, and A. R. Volpe, "Comparative efficacy of two dentifrices containing $5 \%$ potassium nitrate on dentinal sensitivity: a twelve-week clinical study," Journal of Clinical Dentistry, vol. 5, pp. 97-101, 1994.

[51] F. Bohen and J. Lafont, "Dentinal hypersensitivity: clinical evaluation about the efficiency of a new desensitization agent," http://www.septodontusa.com/sites/default/files/Isodan_2.pdf.

[52] W. D. Browning, D. C. N. Chan, K. B. Frazier, R. S. Callan, and J. S. Blalock, "Safety and efficacy of a nightguard bleaching agent containing sodium fluoride and potassium nitrate," Quintessence International, vol. 35, no. 9, pp. 693-698, 2004.

[53] A. J. Charig, Y. Xu, S. Thong, and A. E. Winston, "Comparison of mechanism of action of desensitizing treatments," Journal of Dental Research, vol. 86, Abstract no. 3160, 2008.

[54] N. Conforti, G. W. Battista, D. M. Petrone et al., "Comparative investigation of the desensitizing efficacy of a new dentifrice: a 14-day clinical study," Compendium of Continuing Education in Dentistry, no. 27, pp. 17-28, 2000.

[55] R. L. Cooley and V. A. Sandoval, "Effectiveness of potassium oxalate treatment on dentin hypersensitivity," General Dentistry, vol. 37, no. 4, pp. 330-333, 1989.

[56] R. Docimo, L. Montesani, P. Maturo et al., "Comparing the efficacy in reducing dentin hypersensitivity of a new toothpaste containing $8.0 \%$ arginine, calcium carbonate, and $1450 \mathrm{ppm}$ fluoride to a commercial sensitive toothpaste containing $2 \%$ potassium ion: an eight-week clinical study in Rome, Italy," Journal of Clinical Dentistry, vol. 20, no. 1, pp. 17-22, 2009.

[57] S. C. Frechoso, M. Menéndez, C. Guisasola, I. Arregui, J. M. Tejerina, and A. Sicilia, "Evaluation of the efficacy of two potassium nitrate bioadhesive gels (5\% and $10 \%)$ in the treatment of dentine hypersensitivity. A randomised clinical trial," Journal of Clinical Periodontology, vol. 30, no. 4, pp. 315320, 2003.

[58] D. G. Gillam, J. S. Bulman, R. J. Jackson, and H. N. Newman, "Efficacy of a potassium nitrate mouthwash in alleviating cervical dentine sensitivity (CDS)," Journal of Clinical Periodontology, vol. 23, no. 11, pp. 993-997, 1996.

[59] D. G. Gillam, J. S. Bulman, R. J. Jackson, and H. N. Newman, "Comparison of 2 desensitizing dentifrices with a commercially available fluoride dentifrice in alleviating cervical dentine sensitivity," Journal of Periodontology, vol. 67, no. 8, pp. 737-742, 1996.

[60] A. C. K. Goncalves, S. C. S. Pinto, C. M. M. Silveira et al., "Effects of desensitizing toothpastes on dentin permeability: an animal study," Journal of Dental Research, vol. 89, Abstract no. 1309, 2011.

[61] P. J. Hall, C. P. Horay, P. S. Spradbery, D. Hill, and A. P. Barlow, "Intra-oral potassium dispersion profile of a gel to foam toothpaste," Journal of Dental Research, vol. 86, Abstract no. 0466, 2008. 
[62] B. Van Haywood, W. Frank Caughman, K. B. Frazier, and M. L. Myers, "Tray delivery of potassium nitrate-fluoride to reduce bleaching sensitivity," Quintessence International, vol. 32, no. 2, pp. 105-109, 2001.

[63] V. B. Haywood, R. Cordero, K. Wright et al., "Brushing with a potassium nitrate dentifrice to reduce bleaching sensitivity," Journal of Clinical Dentistry, vol. 16, no. 1, pp. 17-22, 2005.

[64] M. Hodosh, "A superior desensitizer-potassium nitrate," The Journal of the American Dental Association, vol. 88, no. 4, pp. 831-832, 1974.

[65] M. Hodosh, "Current treatment for dentinal hypersensitivity. Potassium nitrate as a desensitizer," The Compendium of Continuing Education in Dentistry, no. 3, pp. S120-121, 1982.

[66] E. Jalalian, N. Meraji, and M. Mirzaei, "A comparison of the efficacy of potassium nitrate and gluma desensitizer in the reduction of hypersensitivity in teeth with full-crown preparations," Journal of Contemporary Dental Practice, vol. 10, no. 1, pp. 66-73, 2009.

[67] H. Kawamata, K. Ohta, T. Saito, and R. Hayman, "Potassium nitrate enhances occlusion of dentinal tubules by nanohydroxyapatite," Journal of Dental Research, vol. 86, Abstract no. 2265,2008 .

[68] C. Lecointre, J. Apiou, P. Marty, and P. Poitou, "Controlled trial of the action of a toothpaste containing nicomethanol hydrofluoride in the treatment of dentine hypersensitivity," Journal of International Medical Research, vol. 14, no. 4, pp. 217222, 1986.

[69] M. Manochehr-Pour, M. Bhat, and N. Bissada, "Clinical evaluation of two potassium nitrate toothpastes for the treatment of dental hypersensitivity," Periodontal Case Reports, vol. 6, no. 1, pp. 25-30, 1984.

[70] K. McCormack and R. Davies, "The enigma of potassium ion in the management of dentine hypersensitivity: is nitric oxide the elusive second messenger?" Pain, vol. 68, no. 1, pp. 5-11, 1996.

[71] N. J. Mordan, D. G. Gillam, N. J. Bock, F. Ley, and F. A. Curro, "ESEM vs. SEM evaluation of desensitising dental products on dentine," Journal of Dental Research, vol. 81, Special Issue A, A373, Abstract no. 3001, 2002.

[72] A. Morris, J. Gallob, P. Amini et al. et al., "Efficacy of a potassium nitrate mouthrinse for relieving dentinal hypersensitivity," Journal of Dental Research, vol. 87, Abstract no. 1575, 2009.

[73] T. Pamir, M. Özyazici, E. Baloğlu, and B. Önal, “The efficacy of three desensitizing agents in treatment of dentine hypersensitivity," Journal of Clinical Pharmacy and Therapeutics, vol. 30, no. 1, pp. 73-76, 2005.

[74] J. M. Peacock and R. Orchardson, "Effects of potassium ions on action potential conduction in A- and C-fibers of rat spinal nerves," Journal of Dental Research, vol. 74, no. 2, pp. 634-641, 1995.

[75] J. M. Peacock and R. Orchardson, "Action potential conduction block of nerves in vitro by potassium citrate, potassium tartrate and potassium oxalate," Journal of Clinical Periodontology, vol. 26, no. 1, pp. 33-37, 1999.

[76] J. C. Pereira, A. D. Segala, and D. G. Gillam, "Effect of desensitizing agents on the hydraulic conductance of human dentin subjected to different surface pre-treatments-an in vitro study," Dental Materials, vol. 21, no. 2, pp. 129-138, 2005.

[77] F. D. Pillon, I. G. Romani, and É. R. Schmidt, "Effect of a $3 \%$ potassium oxalate topical application on dentinal hypersensitivity after subgingival scaling and root planing," Journal of Periodontology, vol. 75, no. 11, pp. 1461-1464, 2004.
[78] D. G. Pol, J. Jonnala, M. Chute, T. Gunjikar, and S. Pol, "Potassium nitrate in the treatment of dentinal hypersensitivity-a mini analysis of studies," Journal of the Indian Dental Association, vol. 4, pp. 399-403, 2010.

[79] K. V. V. Prasad, R. Sohoni, S. Tikare, M. Yalamalli, G. Rajesh, and S. B. Javali, "Efficacy of two commercially available dentifrices in reducing dentinal hypersensitivity," Indian Journal of Dental Research, vol. 21, no. 2, pp. 224-230, 2010.

[80] T. C. Reinhart, W. J. Killoy, J. Love, P. R. Overman, and J. S. Sakumura, "The effectiveness of a patient-applied tooth desensitizing gel. A pilot study," Journal of Clinical Periodontology, vol. 17, no. 2, pp. 123-127, 1990.

[81] S. Salian, S. Thakur, S. Kulkarni, and G. Latorre, "A randomized controlled clinical study evaluating the efficacy of two desensitizing dentifrices," Journal of Clinical Dentistry, vol. 21, no. 3, pp. 82-87, 2010.

[82] A. R. Salvato, G. E. Clark, J. Gingold, and F. A. Curro, "Clinical effectiveness of a dentifrice containing potassium chloride as a desensitizing agent," American Journal of Dentistry, vol. 5, no. 6, pp. 303-306, 1992.

[83] N. Sharma, "A randomized, parallel group clinical study evaluating the efficacy of three desensitizing dentifrices," 2010, http://www.oralscience.ca/fr/documentation/education/ARandomized-Parallel-Group-Clinical-Study-Evaluating-theEfficacy-of-three-Desensitizing-Dentifrices.pdf.

[84] N. Sharma, S. Roy, A. Kakar, D. C. Greenspan, and R. Scott, "A clinical study comparing oral formulations containing 7.5\% calcium sodium phosphosilicate (novamin), 5\% potassium nitrate, and $0.4 \%$ stannous fluoride for the management of dentin hypersensitivity," Journal of Clinical Dentistry, vol. 21, no. 3, pp. 88-92, 2010.

[85] G. Silverman, "The sensitivity-reducing effect of brushing with a potassium nitrate-sodium monofluorophosphate dentifrice," The Compendium of Continuing Education in Dentistry, vol. 6, no. 2, pp. 131-136, 1985.

[86] G. Silverman, J. Gingold, and F. A. Curro, "Desensitizing effect of a potassium chloride dentifrice," American Journal of Dentistry, vol. 7, no. 1, pp. 9-12, 1994.

[87] J. A. Sowinski, Y. Bonta, G. W. Battista et al., "Desensitizing efficacy of colgate sensitive maximum strength and fresh mint sensodyne dentifrices," American Journal of Dentistry, vol. 13, no. 3, pp. 116-120, 2000.

[88] J. Sowinski, F. Ayad, M. Petrone et al., "Comparative investigations of the desensitising efficacy of a new dentifrice," Journal of Clinical Periodontology, vol. 28, no. 11, pp. 1032-1036, 2001.

[89] W. J. Stead, R. Orchardson, and P. B. Warren, "A mathematical model of potassium ion diffusion in dentinal tubules," Archives of Oral Biology, vol. 41, no. 7, pp. 679-687, 1996.

[90] W. J. Tarbet, G. Silverman, J. M. Stolman, and P. A. Fratarcangelo, "Clinical evaluation of a new treatment for dentinal hypersensitivity," Journal of Periodontology, vol. 51, no. 9, pp. 535-540, 1980.

[91] W. J. Tarbet, A. Buckner, and M. M. Stark, "The pulpal effects of brushing with a 5 percent potassium nitrate paste used for desensitization," Oral Surgery Oral Medicine and Oral Pathology, vol. 51, no. 6, pp. 600-602, 1981.

[92] L. Z. Touyz and J. Stern, "Hypersensitive dentinal pain attenuation with potassium nitrate," General Dentistry, vol. 47, no. 1, pp. 42-45, 1999.

[93] W. J. Wang, W. S. Rong, and Y. Liang, "Desensitizing effect of a toothpaste containing potassium citrate," Journal of Dental Research, vol. 87, Abstract no. 2555, 2010. 
[94] N. Wara-aswapati, D. Krongnawakul, D. Jiraviboon, S. Adulyanon, N. Karimbux, and W. Pitiphat, "The effect of a new toothpaste containing potassium nitrate and triclosan on gingival health, plaque formation and dentine hypersensitivity," Journal of Clinical Periodontology, vol. 32, no. 1, pp. 53-58, 2005.

[95] R. Yates, N. X. West, M. Addy, and I. Marlow, "The effects of a potassium citrate, cetylpyridinium chloride, sodium fluoride mouthrinse on dentine hypersensitivity, plaque and gingivitis. A placebo-controlled study," Journal of Clinical Periodontology, vol. 25, no. 10, pp. 813-820, 1998.

[96] R. Yates, R. Ferro, R. G. Newcombe, and M. Addy, "A comparison of a reformulated potassium citrate desensitising toothpaste with the original proprietary product," Journal of Dentistry, vol. 33, no. 1, pp. 19-25, 2005.

[97] G. Orsini, M. Procaccini, L. Manzoli, F. Giuliodori, A. Lorenzini, and A. Putignano, "A double-blind randomized-controlled trial comparing the desensitizing efficacy of a new dentifrice containing carbonate/hydroxyapatite nanocrystals and a sodium fluoride/potassium nitrate dentifrice," Journal of Clinical Periodontology, vol. 37, no. 6, pp. 510-517, 2010.

[98] A. R. Pradeep and A. Sharma, "Comparison of clinical efficacy of a dentifrice containing calcium sodium phosphosilicate to a dentifrice containing potassium nitrate and to a placebo on dentinal hypersensitivity: a randomized clinical trial," Journal of Periodontology, vol. 81, no. 8, pp. 1167-1173, 2010.

[99] S. Minkoff and S. Axelrod, "Efficacy of strontium chloride in dental hypersensitivity," Journal of Periodontology, vol. 58, no. 7, pp. 470-474, 1987.

[100] T. Nagata, H. Ishida, H. Shinohara et al., "Clinical evaluation of a potassium nitrate dentifrice for the treatment of dentinal hypersensitivity," Journal of Clinical Periodontology, vol. 21, no. 3, pp. 217-221, 1994.

[101] T. Schiff, M. Dotson, S. Cohen, W. De Vizio, J. McCool, and A. Volpe, "Efficacy of a dentifrice containing potassium nitrate, soluble pyrophosphate, PVM/MA copolymer, and sodium fluoride on dentinal hypersensitivity: a twelve-week clinical study," Journal of Clinical Dentistry, vol. 5, pp. 87-92, 1994.

[102] T. Schiff, M. Dos Santos, S. Laffi et al., "Efficacy of a dentifrice containing 5\% potassium nitrate and 1500 PPM sodium monofluorophosphate in a precipitated calcium carbonate base on dentinal hypersensitivity," Journal of Clinical Dentistry, vol. 9, no. 1, pp. 22-25, 1998.

[103] T. Schiff, Y. P. Zhang, W. DeVizio et al., "A randomized clinical trial of the desensitizing efficacy of three dentifrices," Compendium of Continuing Education in Dentistry, no. 27, pp. 4-28, 2000.

[104] G. Silverman, E. Berman, C. B. Hanna et al., "Assessing the efficacy of three dentifrices in the treatment of dentinal hypersensitivity," Journal of the American Dental Association, vol. 127, no. 2, pp. 191-201, 1996.

[105] J. A. Sowinski, G. W. Battista, M. E. Petrone et al., "A new desensitizing dentifrice-an 8-week clinical investigation," Compendium of Continuing Education in Dentistry, no. 27, pp. 11-28, 2000.

[106] W. J. Tarbet, G. Silverman, J. M. Stolman, and P. A. Fratarcangelo, "An evaluation of two methods for the quantitation of dentinal hypersensitivity," The Journal of the American Dental Association, vol. 98, no. 6, pp. 914-918, 1979.

[107] K. F. Schulz, "Assessing allocation concealment and blinding in randomised controlled trials: why bother?" Evidence-Based Mental Health, vol. 3, no. 1, pp. 4-5, 2000.
[108] D. Bowers, "Testing hypotheses about the difference between two population parameters," in Medical Statistics from Scratch: An Introduction for Health Professionals, chapter 12, pp. 141-145, John Wiley \& Sons, London, UK, 2008.

[109] D. Bowers, "Doing it right first time-designing a study," in Medical Statistics from Scratch: An Introduction for Health Professionals, chapter 6, pp. 71-90, John Wiley \& Sons, London, UK, 2008.

[110] D. Gillam, "Making sense of dentine hypersensitivity," Dental Practice, vol. 47, no. 10, p. 12, 2009.

[111] D. G. Gillam, "Diagnosis and management of dentine hypersensitivity," Dental Tribune, vol. 10, no. 7, pp. 11-12, 2009.

[112] D. G. Gillam, "Management of dentine hypersensitivity: a guide to treatment options," Oral Health Report, vol. 3, pp. 8-12, 2010.

[113] U. Zappa, "Self-applied treatments in the management of dentine hypersensitivity," Archives of Oral Biology, vol. 39, no. 1, pp. S107-S112, 1994.

[114] M. Addy and P. Mostafa, "Dentine hypersensitivity. II. Effects produced by the uptake in vitro of toothpastes onto dentine," Journal of Oral Rehabilitation, vol. 16, no. 1, pp. 35-48, 1989.

[115] M. Ide, R. F. Wilson, and F. P. Ashley, "The reproducibility of methods of assessment for cervical dentine hypersensitivity," Journal of Clinical Periodontology, vol. 28, no. 1, pp. 16-22, 2001.

[116] F. A. Curro, M. Friedman, and R. S. Leight, "Design and conduct of clinical trials on dentine hypersensitivity," in Tooth Wear and Sensitivity, M. Addy, G. Embery, W. M. Edgar, and R. Orchardson, Eds., pp. 299-314, Martin Dunitz, London, UK, 2000 . 


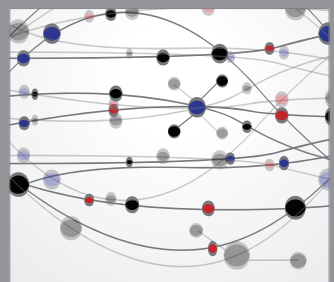

The Scientific World Journal
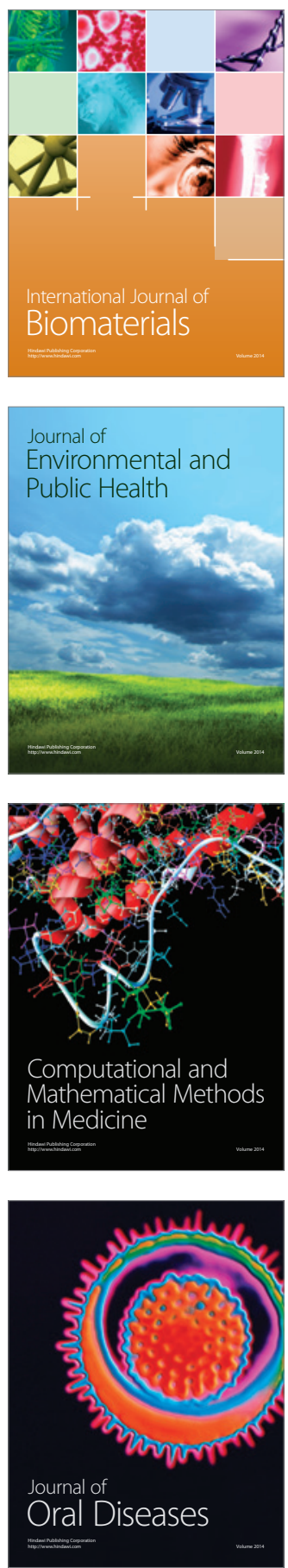
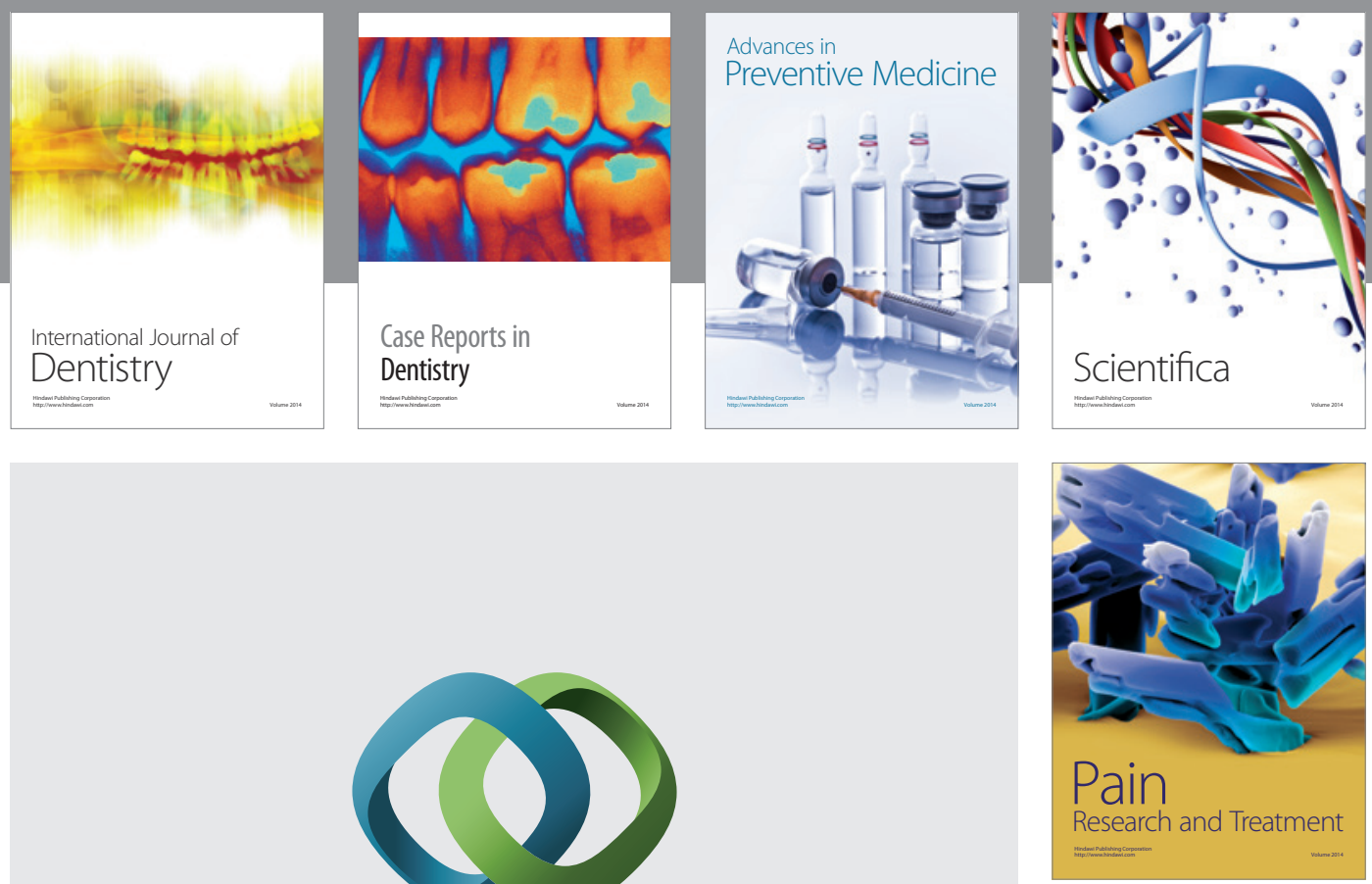

\section{Hindawi}

Submit your manuscripts at

http://www.hindawi.com
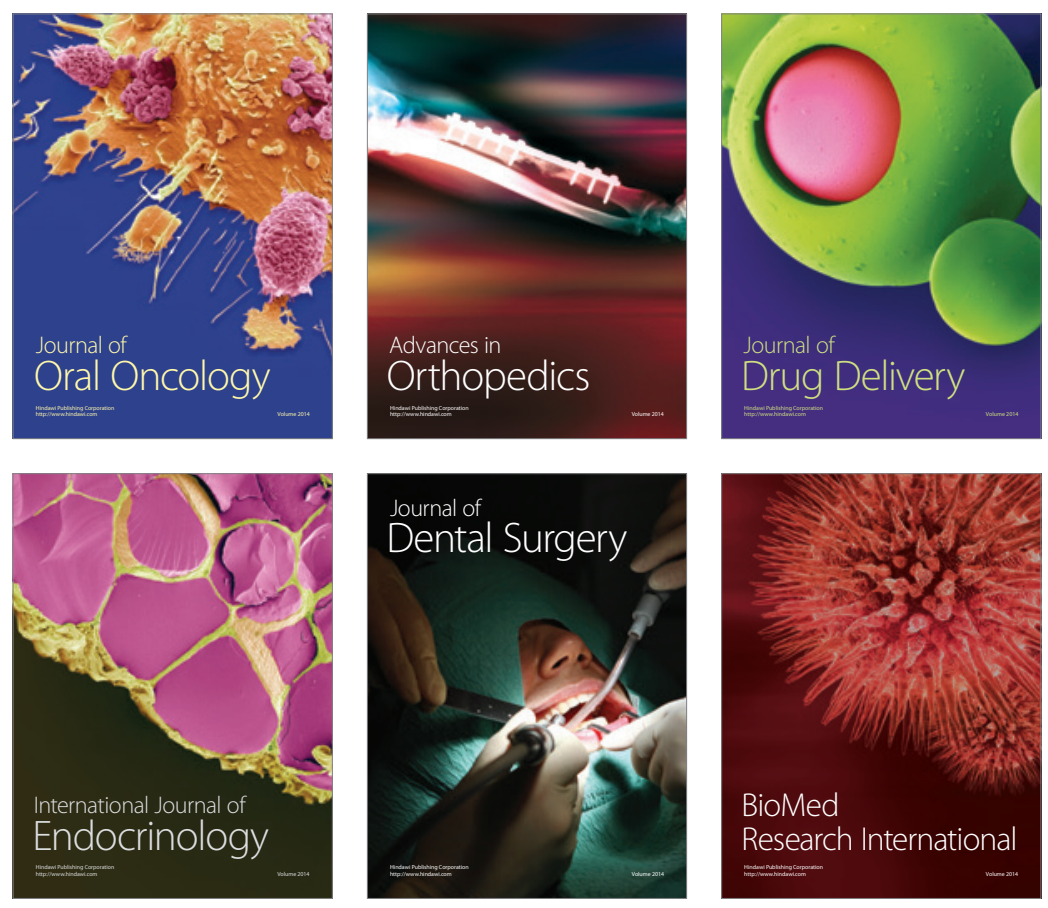

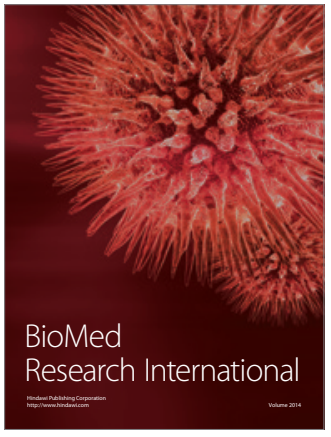

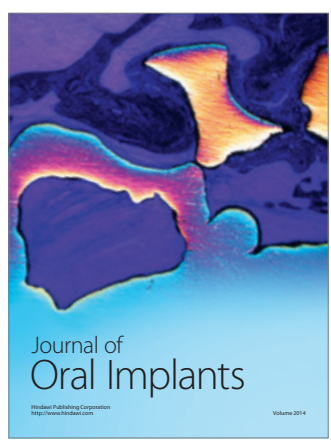
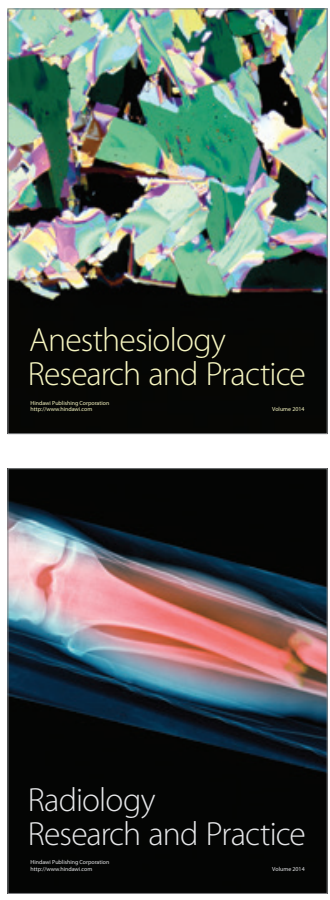